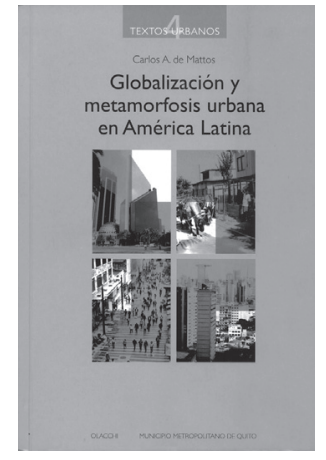

\section{Carlos de Mattos. Globalización y metamorfosis urbana en América Latina}

\author{
Quito: Organización Latinoamericana y del Caribe de \\ Centros Históricos (OLACCHI) y Municipio del Distrito \\ Metropolitano de Quito (MDMQ), 2010.374 p.
}

\author{
Andrés Núñez 1
}

A su vasto y dilatado trabajo, el profesor e investigador uruguayo Carlos de Mattos, agrega un nuevo título, Globalización y metamorfosis urbana en América Latina, gestionado y editado por la Organización Latinoamericana y del Caribe de Centros Históricos y el Municipio del Distrito Metropolitano de Quito, Ecuador, y que forma parte de la Colección de Textos Urbanos, en una impecable edición de casi 400 páginas. Como lo indica el propio autor, se trata de una serie de escritos, elaborados entre 1990 y 2010, que permiten dar coherencia al propósito central de analizar y reflexionar en torno al desarrollo y gestión territorial y urbana en América Latina. En forma más específica, en cómo esa gestión y desarrollo se desenvuelve y manifiesta en una dinámica capitalista -social, económica y política- que ha venido estructurando y condicionando el devenir de los territorios y ciudades en esta parte del mundo.

El libro, editado recién en junio del presente año, se divide en dos secciones. La primera, titulada Dinámica territorial y gestión urbana, que se ubica preferentemente en una temporalidad que antecede a la siguiente sección, se centra básicamente en determinadas problemáticas que fueron impactando al conjunto del territorio latinoamericano al agudizarse los procesos de urbanización, de concentración territorial, tanto productiva como demográfica así como de desigualdad al interior del propio continente. La segunda parte, denominada Globalización y trasformación territorial urbana, siendo un complemento indiscutible de la anterior, se aboca en lo esencial en un proceso en curso como lo es la huella, en algunos casos muy notoria, que sobre las ciudades y regiones metropolitanas ha ido dejando lo que él llama la "nueva fase de modernización capitalista" (en esto siguiendo a Castells, Harvey, aunque no se excluyen otros autores) a partir de los procesos de liberalización económica y de evolución tecnológica y digital (la informalización) en una dinámica de creciente globalización. Esta última fase la sitúa en las últimas décadas del siglo $X X$, una vez terminados los discursos desarrollistas posteriores a la crisis capitalista de 1929.

Lo primero que es necesario exponer es que el libro, a pesar de presentar artículos fechados en los inicios de la década de 1990, resulta de una actualidad desbordante. EI autor realiza una conjugación Ilamativa de su literatura a fin de exponer y dar coherencia a un proceso histórico intacto que precisamente, como su título lo indica, lleva a comprender en buena parte la metamorfosis urbana que se ha venido produciendo y viviendo en Latinoamérica en las últimas décadas ${ }^{2}$. Expresado en otras palabras, parafraseando al filósofo e historiador francés Michael Foucault, De Mattos colabora sustancialmente en la comprensión del por qué y cómo han aparecido determinados objetos posibles de conocimiento y poder, para el caso, la imagen de la ciudad y lo urbano en el contexto del paradigma capitalista.

1 Doctor en Historia, Pontificia Universidad Católica de Chile (Chile).E-mail: andresnunezg@gmail.com

2 Algunos autores han Ilegado a determinar que se trata de una "nueva revolución urbana", remitiéndose con ello inevitablemente a la planteada anteriormente por H. Lefebvre en 1972. 
Desde esta perspectiva, es decir, de lo contingente de su publicación, Ilama positivamente la atención que el profesor De Mattos entienda su oficio como la investigación que trasciende su campo disciplinar original, la arquitectura. En su exposición, es fácil percibir en él un escritor multidisciplinario y dinámico, en tanto, su análisis es, a la vez, histórico, económico, geográfico y, podríamos sin duda decir, sociológico. En cierto modo, él mismo lo deja ver cuando dice que el contenido de este conjunto de escritos es el resultado de un permanente diálogo, discusión y reflexión con una serie de interlocutores, colegas y alumnos, que a través de estos años han interactuado con él en charlas, cursos, seminarios, coloquios y pasillos de los dos de sus principales (e históricos) centros laborales, el Instituto Latinoamericano de Planificación Económica y Social (ILPES - ONU) y el Instituto de Estudios Urbanos y Territoriales de la Pontificia Universidad Católica de Chile. Desde ambos ámbitos, su cercanía al diálogo con profesionales de las disciplinas antes mencionadas debe haber sido muy relevante al momento de ir definiendo sus hipótesis de trabajo. Lo anterior, como dijimos, se ve reflejado a lo largo del libro.

Detengámonos en algunos aspectos que resultan centrales en su exposición. Al respecto, es necesario resaltar y no olvidar que su interés principal está estructurado a partir de los problemas urbanos latinoamericanos, en cómo estos se fueron y han ido configurando y las razones o causas de sus cambios. En este contexto, más específicamente, en el análisis y relación del proceso de modernización capitalista -en sus distintas fases o etapas- y la trasformación urbana resultante de aquel proceso.

En general, en el marco del proceso de modernización capitalista, lo primero que llama la atención -y que De Mattos, en cierto modo, utiliza como una suerte de contrapunto- es la identificación y contextualización precisa y clara de aquel momento histórico (fines siglo XIX y principios del XX) que con base en el proceso de industrialización deriva en lo que Lefebvre ha Ilamado la sociedad urbana, a fin de reflejar el cambio radical que se produjo a nivel mundial en las grandes áreas urbanas. Es decir, para utilizar la palabra usada por De Mattos, aquella metamorfo- sis urbana de gran nivel resultante de aquella industrialización, que llevó a modificar el escenario global en la forma de comprender y representar la ciudad. Solo unas cifras dan claramente cuenta del asunto: entre 1900 y 1930, la población de San Pablo pasó de 240.000 a 1.100 .000 , en Buenos Aires de 606.000 a 2.178.000, y en Santiago de Chile de 333.000 a 700.000 habitantes.

Con la crisis de 1929, el desarrollo capitalista deriva en una mutación que no deja de ser interesante y llamativa, ya que, lejos de anularse como sistema, se adapta al nuevo escenario aferrándose a la planificación. Paradójicamente, desde la perspectiva de la posición actual del libre mercado, lejos de asumir una postura como la soviética, con la revolución aún muy fresca, el mundo occidental capitalista encontró en esas décadas de 1930-1940 una respuesta a la crisis liberal en lo que denominó la Economía Dirigida y pasó a reconocerse, en cierto modo buscando justificaciones, con el nacimiento de lo que se comenzó a llamar Estado moderno.

Este proceso y su impacto sobre el territorio y las ciudades De Mattos lo trabaja, desde nuestro punto de vista, en forma muy clara y profunda en el capítulo denominado "De la planificación a la gobernanza: hacia un nuevo modo de gestión urbana". A través de él, expone el proceso que sigue a la crisis del 29 y el posterior discurso teórico-ideológico que surge con el liberalismo a partir de la década de 70 del siglo pasado, a fin de, precisamente, "liberar" los capitales y evitar la intervención -es decir, lo contrario a la racionalización que supuso la planificación- donde la competividad y el crecimiento económico, a partir del capital privado, fuesen ahora los pilares del nuevo devenir. Aquella liberalización de capitales supuso -y, por cierto, supone- una suerte de nueva configuración mundial a partir de la globalización, llegando a ser considerada incluso desde ciertos puntos de vista más radicales como la última fase del capitalismo. Algunas de las principales características de este nuevo escenario -llamado la época de la gobernanza- son trabajadas en el capítulo Reestructuración económica, nuevas estrategias empresariales y mutaciones territoriales en América Latina. En general, ellas se identifican con: neoliberalismo, valorización del capital y del individuo, crecimiento eco- 
nómico, liberalización del comercio exterior, reducción del gasto público, disciplina fiscal, igualdad de oportunidades a los diversos actores económicos, Estado descentralizado, supervisor, neutral y subsidiario, entre otros, todos discursos que pueden encontrarse a diario en la prensa escrita y otros medios, cual acuerdo o consenso representacional.

De esta suerte, el autor identifica dos procesos que resultan sustanciales para comprender los cambios que se produjeron a nivel urbano en América Latina en las últimas décadas del siglo XX. El primero, una revolución técnica, o lo que Castells ha denominado la Informacionalización, es decir, comunicaciones en tiempo real, digitalización. Un segundo cambio importante nos remite a un aspecto más bien teórico y dice relación con la consolidación ideológica de la liberalización de los capitales y, desde esta perspectiva, de una valorización de los intercambios de capital a nivel, ahora, global. Es decir, lo que se ha conocido como la globalización financiera .

Ambas situaciones han, entonces, impuesto un nuevo modelo de desarrollo que, como nos ilustra el autor, ha tenido impactos territoriales y urbanos evidentes. Tan notorios que, como titula De Mattos en el capítulo 6, texto de reciente producción, ellos han ido generando "una nueva forma urbana". Allí expresa: "Las tendencias que caracterizan a la metamorfosis vivida por buena parte de las grandes ciudades en proceso de globalización desde fines del siglo pasado, más allá de la identidad específica de cada una de ellas, han sustentado una evolución hacia una nueva forma o patrón genérico de urbanización, el cual presenta diferencias sustantivas con aquel que se había impuesto en lo que se conoce como la ciudad industrial. Los factores que tuvieron una incidencia decisiva en el desencadenamiento de esta metamorfosis, solamente pueden explicarse en el contexto de los cambios constitutivos de la nueva dinámica de acumulación y crecimiento globalizada".

Desde esta lógica de análisis, es decir, desde la plataforma impulsada por "la explosiva intensificación de la conectividad, la configuración y continua expansión de un espacio mundial de acumulación, la financierización prácticamente total de la economía mundial, la imposición de nuevas condiciones para la competividad y la flexibilización y segmentación de los mercados de trabajo", entre otros aspectos, las ciudades o áreas urbanas han pasado a ser unidades geográficas esenciales. En otras palabras, el nuevo modelo de desarrollo neoliberal funciona (e impacta) desde las ciudades, que en un nuevo horizonte cultural, derivan hacia "lo urbano".

Esta nueva estructuración capitalista genera, por tanto, lo que el propio De Mattos llama "una nueva arquitectura productiva organizada en red", en este caso, a través de una red mundial de ciudades. La pregunta es, por tanto, ¿qué tipo de ciudad o qué nueva forma urbana surge a partir de esta nueva fase de desarrollo capitalista? La respuesta es analizada en los dos últimos capítulos, Globalización y metamorfosis metropolitana en América Latina. Hacia una nueva forma urbana y Santiago de Chile en la globalización: reestructuración productiva y metamorfosis urbana, donde, en el fondo, se analiza, siguiendo en cierto modo a Lefebvre, el paso de "la ciudad a lo urbano".

Entre otras características, esta nueva forma urbana presenta una tendencia hacia la periurbanización y a la policentralización, es decir, una disposición a la coexistencia de varios centros o focos nodales así como la indefinición de sus límites, otrora claramente identificados. Es lo que se viene conociendo como "la ciudad difusa". Aquella idea tan recurrente desde la década del 80 de vivir en el campo, pero en la ciudad a la vez, es un buen ejemplo de esta ampliación de la ciudad hacia lo urbano. Con ello, expone De Mattos, nos hemos insertado y encaminado hacia la metropolitanización de la ciudad donde todo se vuelve "difuso, desigual y fragmentado".

Es en este contexto que Santiago ejemplifica algunas características principales de aquella metropolitanización: menos población en el centro, crecimiento en zonas del borde o periurbano (Pirque, Buin, pero también Melipilla, incluso Rancagua), aumento de consumo de tierra per cápita y baja de la densidad urbana de la ciudad, entre otras.

En definitiva, según palabras del propio autor, "la aglomeración metropolitana emer- 
gente puede ser observada como la lógica y transitoria metamorfosis ocasionada por un nuevo impulso de modernización capitalista, en la que se ha originado una dinámica económica, fuertemente marcada por la informacionalización y la globalización. En lo esencial, lo urbano emergente se presenta como un organismo configurado por una dinámica reticular, cuya dilatación dispersa y discontinua, desborda y desdibuja los límites de la mancha urbana original, imponiendo una morfología policéntrica sin fronteras precisas, marcada por la aparición fragmentada de diversos artefactos que modifican la estructuración del espacio urbano y la aparición de su paisaje". Tal panorama no debe olvidarse, surge de su tesis medular que "en cada período histórico, las grandes transformaciones territoriales son consecuencia básicamente de la dinámica de acumulación y crecimiento desencadenada por el modelo de desarroIlo capitalista entonces vigente", sea este industrial-desarrollista o neoliberal-informacionalista. Desde esta perspectiva, concluye, la metamorfosis debería interpretarse como continuidad y cambio, donde distintas fases representan una misma estructura que sustenta y justifica los cambios.

El autor, en consecuencia, nos deleita con un "viaje" muy ilustrativo sobre los cambios de la ciudad, desde la revolución industrial a la fase neoliberal, todas etapas de un modelo capitalista que, inevitablemente, la impacta y la transforma, Ilegando incluso uno a preguntarse si la "ciudad actual" es realmente una ciudad o definitivamente, dada su metamorfosis, nos encontramos frente a otro tipo de representación cuya identidad no pueda ser ya comparable con formaciones urbanas precedentes.

Sin lugar a dudas, un trabajo sugerente e incitante, de enorme actualidad que aparece como muy necesario e indispensable al momento de buscar comprender la relación globalización y cambios urbanos en América Latina. 